\title{
Impact of Climate Change on Food Security in Bangladesh
}

\section{Md. Humayun Kabir' ${ }^{1}$ Zobaer Ahmed ${ }^{1}$ and Rabia Khan ${ }^{2 \star}$}

${ }^{1}$ University of Dhaka, Bangladesh

${ }^{2}$ Kohat University of Science and Technology, Pakistan

\begin{abstract}
The paper contains the analyses of the impacts of climate change on food security and adaptation of new strategies to fight against the different causes of climate changes in the Kalapara Upazila of Patuakhali District in Bangladesh. The paper shows current climate change scenarios for Kalapara, analyses the relationship between climate change scenarios and adaptation of relevant measures and strategies by the cultivators which adequately helps in reducing the risks of climate change and improves livelihoods. It also described the adaption strategies to climate change and their application for food security. Historical changes in the weather pattern by different natural disasters like flood, storm surge, drought etc. have any impact on the agricultural practices of that District and how the adaptation option are rightly utilized that has been analyzed in this paper. To support the analysis a questionnaire survey was conducted to gather farmer perceptions of what different strategies should take to fight against the climate changes with some demographic conditions of the farmers' families. The paper presented that the education level of the present generation of farmers is gradually increasing and they have perceptions that show the temperature is rising, timely rainfall is not available and crop production seasons are shifting. The adaptation measures followed by the local people are increasing their capability to fight with climate change problems and with the course of time the food security of the area is enriched.
\end{abstract}

Keywords: Food security; Climate change; Fossil fuels; Ecosystems; Agriculture; Green-house

\section{Introduction}

Across 250 years, deforestation, combustion of fossil fuels, and production of agricultural yield atmospherically; the concentration of carbon dioxide $\left(\mathrm{CO}_{2}\right)$ and different greenhouse gases to rise considerably. Climate change has gain world attention because it evolves as the most important challenge of the century. Climate change definition is inevitable in the foregoing; it means all changes within the climate as a result of human activities or natural variations [1]. The planet is encircled by layer of gases that act just like the glass wall (earth blanket) and ceiling of green-house. These questionable greenhouse gases are important to sustain life on earth. They let the sun ray penetrate however, stop abundant of the warmth from escaping, keeping the earth heat enough to permit life. However, drawback that we tend to face these days is that the blanket of the green-house gases that happens naturally within the layer is apace obtaining thicker resulting from increased emissions of greenhouse gases and this lead to the speedy warming of the world's climate.

Climate change, apparently is change within the mean values of climate measure by component such as; rain, temperature, over long amount of your time typically fifty years, (climate change/global climate change/temperature change) is that the important change within the state of the climate of an area that may be known by change within the mean associated or within the variability of its properties that persist for an extended amount ineffably decades or longer IPCC (2011). Temperature change may be a phenomenon that has been accepted globally as a truth of life. This implies that it is a matter of indisputable fact that can continuously be subjected to natural dynamism or changes.

There are many assumptions and have been made from a wide range of climate model simulations for example, the scenario assumes that humans worldwide are likely to make more sustainable development choices if wider range of technologies for producing energy with greater efficiency will be used in the future. Carbon emissions are forecasted to be increased from current rate of around 9 billion metric tons each year to around 12 billion tons each year until 2040, and after that it will again gradually decline to 5 billion tons each year by the year 2100 [2] The main reason for this temperature increase is carbon dioxide and other heat-trapping "greenhouse" gases that human activities produce. The biggest source of added carbon dioxide is from people burning coal and other fossil fuels. Climatic changes are putting very negative effect on many things such as herbs like Satu, silajit, Bhase, timur, amala, panch aule, ritha, bel are deteriorating and transferring to higher altitude ranges whereas green grass has also deteriorated severely in the Himalayan region of Mustang [3].

On the other hand, fast increase in greenhouses has both positive and negative effects on people, society, and the environment-including plants and animals because many of the major greenhouse gases stay in the atmosphere for tens to hundreds of years after being released, their warming effects on the climate persist over a long time and can therefore affect both present and future generations [4]. Consequently, the rate of change today is unprecedented in human history. $21^{\text {st }}$ Century ecosystems and their component species are faced simultaneously with fragmented landscapes and climate change, not allowing species to adapt to new conditions [5]. Tracing this back into antiquity; Asian nation may be a playground country of oftentimes stirring natural disasters and these natural disasters became moniker to Asian nation, disasters like droughts, coastal erosions, flooding, tropical cyclone and storm surges [6]. Food security is the state achieved when food systems operate such that "all people, at all times, have physical and economic

"Corresponding author: Rabia Khan, Kohat University of Science and Technology, Pakistan, Tel: 0922-52914674; E-mail: rabia.pk123@gmail.com

Received July 11, 2016; Accepted August 25, 2016; Published September 03 2016

Citation: Kabir MH, Ahmed Z, Khan R (2016) Impact of Climate Change on Food Security in Bangladesh. J Pet Environ Biotechnol 7: 306. doi: 10.4172/21577463.1000306

Copyright: $\odot 2016$ Kabir MH, et al. This is an open-access article distributed under the terms of the Creative Commons Attribution License, which permits unrestricted use, distribution, and reproduction in any medium, provided the original author and source are credited. 
access to sufficient, safe, and nutritious food to meet their dietary needs and food preferences for an active and healthy life" [7]. According to [8] "Food security exists when all people at all times have physical or economic access to sufficient, safe and nutritious food to meet their dietary needs and food preferences for an active and healthy life". Food security is influenced by four key dimensions: availability of sufficient food; economic, physical and social access to the resources needed to acquire food; stability of this availability and access; and utilization, including nutrition, food safety and quality [9].

The rest of the paper is organized in following sections: 1) Importance of Agriculture to Bangladesh 2) Adaptation Techniques in agriculture to avoid Adverse Impact of Climate Change 3) Impact of Climate Change on Food Security/Agriculture in Bangladesh 4) Conclusion 5) References.

\section{Importance of agriculture to Bangladesh}

Agriculture in Bangladesh is influenced by seasonal characteristics and climatic variables such as temperature, rainfall, humidity, day length etc. Production of crops, particularly rice, is often constrained by different climatic hazards such as floods, droughts, soil and water salinity, cyclones and water surges [10].

Global expanding populations and limited space are key hurdles to the attainment of food security and poverty reduction. Climate change - increasing temperatures and causing weather extremes - adds to the challenge. There is now a clear consensus within climate change circles that due importance must be given to agricultural needs, and within agricultural circles that climate change must be incorporated in to future climate change negotiations [11]. A large number of the population live below the poverty line in rural Bangladesh due to an increase in the population, fragmentation and loss of land to other sectors (approximately one per cent annually), and limited job opportunities [11]. Increase in population leads to more virtually saturated agricultural land having limited capacity to increase the food production [12].

At the national scale, Bangladesh meets its food requirements through domestic production, imports and food aid. While imports and domestic production have increased, the flow of food aid started to decrease in 2000-01 as the self-sufficiency targets of producing food grains met for first time in the history of Bangladesh. In the year 19902000 , the total food aid was 870 ; in 2000-2001 it was 479; in 2002-2003 it was 242 and this is how it kept on decreasing with time [13].

The role of agriculture and domestic food production in food security cannot be overemphasized given the country's low income, recurrent natural calamities, and the increasing international prices of food commodities. According to estimates made in the (BARC) Bangladesh Agricultural Research Council [14,15], a surplus of 1.213 million tons of food grains will be reached by 2015, but an overall deficit of all others food items will be present [16-23].

According to Lagos [15] in the MY 2015/16 (May-April) rice production is projected at 34.8 million metric tons (MMT) on higher yields and acreage. MY 2015/16 (July-June) wheat production is estimated at 1.3 MMT. MY 2014/15 rice and wheat production estimates are unchanged at 34.5 and 1.3 MMT, respectively. MY 2015/16 wheat imports are estimated at 3.8 million tons on expectations of low international wheat prices and strong domestic demand. Post raised MY 2014/15 wheat imports to 3.5 MMT on strong import pace. MY $2014 / 15$ rice imports were raised to 1.1 MMT on strong import pace. MY 2015/16 (May-April) rice production is projected at 34.8 MMT on higher yields. MY 2015/16 (July-June) wheat production is estimated at 1.3 MMT. MY 2015/16 wheat imports are estimated at 3.8 million tons on expectations of low international wheat prices and strong domestic demand [24-36].

According to Lagos [15], assuming a normal monsoon, MY 2015/16 (May-April) rice production is projected at 34.8 million metric tons (MMT). According to media reports, Bangladeshi officials noted that preliminary official data shows an increase in Boro rice acreage and production. The MY 2014/15 rice production estimate is unchanged; Aman acreage is down slightly due to floods in northern Bangladesh. Adaptation Techniques in agriculture to avoid Adverse Impact of Climate Change [37-45].

Adaptation is an unconstrained approach to adapt up to changing circumstance for avoiding unexpected losses [16]. There are different sorts of adaptation. All kind of adaptation type has the respective application in terms of the adverse effects.

Structural adaptation: Structural modification means taking some fundamental measures to lessen the impacts of environmental change. Structural adjustment is immoderate approach and not for the most part material. For ensuring food security from the unfavorable impacts of environmental change generation of the sustenance things must be expanded. For doing this job polder, floodgate door, torrent, deluge water gathering, and so on must be produced in the beach front zone [16,46-56].

Non-Structural adaptation: This kind of adjustment is considered as the delicate adjustment. Scattering of the appropriate and applicable data to the people, conveying issues to light among the people, thus on is joined in this sort. Migration from high danger region to the less peril zone is in like manner considered as the non-basic adjustment [16,57-70].

Expectant adaptation: There is an aphorism that says prevention is better than cure. This is the major point of expectant adjustment. Sooner or later more groups can take the exercises to lessen unfavorable impacts of environmental change before encountering the outcomes. This sort of adaption is appropriate for the creating countries like as Bangladesh for absence of financing [16].

Reactive adaptation: Post calamity adjustment infers the responsive adjustment. Choices are taken in the wake of considering the results of the calamities. This is adjustment is excessive and tedious. Areas influenced are identifier firstly than the correct steps are taken to ensure the sustenance security from the environmental change [16]

Autonomous and planned adaptation: In its 2007 report (Ch.: 2, pg. 5), FAO made the difference between two adaptations i.e. autonomous, which is a micro-farm level and planned which is called macro-policy level. Illustrations of autonomous adaptation to environmental change incorporates changes in planting dates, generation of distinctive yield diversities or species, changes in the usage of irrigation and water supply, variations in the use of different inputs or in farm administration such as fertilizer, tillage methods, and grain drying. Planned adaptations are division wide changes in procedures or frameworks to manufacture atmosphere flexibility or to elevate shifts in assets to a more proficient use under environmental change impacts. Samples of planned adaptation includes focusing the variations in food insecurity, distinguishing proof of vulnerabilities, reassessment of agrarian research requirements, fortifying of agribusiness augmentation and correspondence frameworks, modifications in item $\&$ trade strategy, and expanded education and training [17]. 
Citation: Kabir MH, Ahmed Z, Khan R (2016) Impact of Climate Change on Food Security in Bangladesh. J Pet Environ Biotechnol 7: 306. doi: 10.4172/2157-7463.1000306

\section{Impact of climate change on food security/agriculture in Bangladesh}

Agricultural in Bangladesh has been greatly influenced by seasonal characteristic and climatic variables such as temperature, rainfall, humidity, day length, etc. Crop agriculture is often constrained by different hazards and disasters such as floods, droughts, soil and water salinity, cyclones and storm surges [18].

According to Hossain [19], the Geophysical Fluid Dynamics Laboratory (GFDL) model predicted an approximate $17 \%$ decline in overall rice production for Bangladesh and as high as a 61 percent decline in wheat production under a $4^{\circ} \mathrm{C}$ change in temperature. The highest impact would therefore be on wheat followed by rice (Aus variety). The Canadian Climate Change Model (CCCM) also predicted a significant fall in food-grain production. Extreme temperature due to climate change would affect livestock. High temperatures cause great discomfort, decrease feed intake and alter nutrient metabolism, leading to high loss of energy. The combined effects of discomfort and nutrient metabolism reduce animals' productivity, resulting in financial losses for the farmers. Apart from extreme temperature, natural disasters such as cyclones and tidal surges, as mentioned previously, cause immense loss and suffering to livestock through destruction of forage crops as well as shelter [71-80].

Despite several studies on specific issues, the probable impact of climate change on many other food and non-food goods, (such as jute) is something of an unknown in Bangladesh currently. In terms of impacts, risks and vulnerabilities, Bangladesh could be divided into regions:

According to Karim et al., clearly, a shortfall in food grain production would severely threaten food security in Bangladesh. At the same time, different models diverge concerning the combined effects of climate change. For instance, carbon dioxide fertilization could facilitate food grain production Moreover, doubling of atmospheric concentrations of $\mathrm{CO}_{2}$, in combination with a similar rise in temperature, could result in an overall 20 per cent rise in rice production and 31 per cent decline in wheat production. It has been proposed that Boro rice would enjoy good harvests under a severe climate change scenario with the doubling of atmospheric concentration of CO [20]. The apparent increase in yield of Boro (dry season paddy generally grown under irrigated conditions and including high-yielding varieties) and other crops might be constrained by moisture stress, however. A 60 per cent moisture stress on top of other effects might cause as high as a 32 per cent decline in Boro yield, instead of having an overall 20 per cent net increase. It is feared that moisture stress would be more intense during the dry season, which might force Bangladeshi farmers to reduce the area for Boro cultivation. Under a severe (4oC temperature increase) climate change scenario, the potential shortfall in rice production could exceed 30 per cent from the trend, while that for wheat and potato could be as high as 50 per cent and 70 per cent respectively [20] (Table 1).

To test the effect of the climate change on the food availability in current year. In this connection the hypothesis was set as under:
$\mathrm{H}_{\mathrm{o}}$ : Climate change experience does not have significant impact on food security.

$\mathrm{H}_{1}$ : Climate change experience has significant impact on food security.

To compute the climate change variability level of each household the above table is followed with scale of measurement. The information of this table gives an overview about the climate change severity that was the key area of experiment to compare data provided by the household for the last 30 years. The new scale must take into consideration the fact that recent year climate changes have more impact on climate change severity than older years. It was decided to calculate a weighted average of the different climate change severity scores. 2015 climate change events have a weight of one (1) and the climate change events of 1991 a weight close to zero (0). The weight is calculated as followed for the events that happened in the year $\mathrm{x}$ the weight is $1-(2015-\mathrm{x}) /$ (2015-1991). The year 2015 is considered the maximal year and 1991 the minimal year.

We first considered the severity as a quantitative variable and see if it has any effect on food availability. To analyze this new variable, we decided to plot the Q-Q plot. We can clearly see how close the expected normal value to the observed value. We can suggest then the normality of the variable. The descriptive statistics tables confirm that based in the kurtosis and skewness and assert that in all the households that participated in the survey (Figures 1 and 2).

Then to express the food availability we choose to calculate the food availability percent which is equal to the percent of months on which there is sufficient amount of food during the current month. a ratio equal to 1 means that food security is satisfied in all the months of the current year which is better than a family having a ratio of $10 \%$ meaning they satisfied their needs in only 1.2 month during that year:

The new variable is calculated based on the variables on the SPSS file as follow:

Food availability $=($ Q.10_January- 1$)+($ Q.10_February- 1$)+$ (Q.10_March- 1) + (Q.10_April- 1) + (Q.10_May- 1) + (Q.10_June- 1) $+\left(\mathrm{Q} .10 \_J u l y-1\right)+\left(\mathrm{Q} .10 \_\right.$August- 1$)+\left(\mathrm{Q} .10 \_\right.$September- 1$)+\left(\mathrm{Q} .10 \_\right.$ October-1) + (Q.10_November-1) + (Q.10_December- 1) $) / 12) * 100$

To analyze this new variable, we decided to plot the Q-Q plot. We can clearly see how close to the expected normal value is close to the observed value. We can suggest then the normality of the variable. The descriptive statistics table confirms that based in the kurtosis and skewness and asserts that in all the households that participated in the survey. The score is at least equal to $50 \%$ which means that they satisfy their needs in at least half a year with a mean of $80.16 \%$ which is pretty acceptable. There is a missing value we decided to replace it with the mean static method, which exchange the missing value with mean (Figure 3).

\section{Conclusion}

Adaptation has an important role in reducing impacts of climate

\begin{tabular}{|c|c|c|c|c|c|c|c|c|c|c|}
\hline & 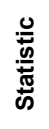 & 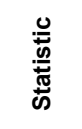 & 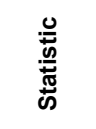 & 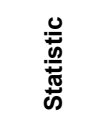 & 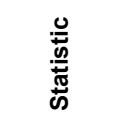 & 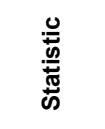 & 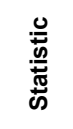 & $\begin{array}{l}\text { ᄒे } \\
\text { யे } \\
\text { ரे } \\
\text { के }\end{array}$ & 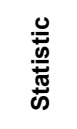 & $\begin{array}{l}\text { ᄒ̀ } \\
\text { ஸे } \\
\text { ப் } \\
\text { के }\end{array}$ \\
\hline Food availability & 79 & 50.00 & 100.00 & 80.1688 & 10.18908 & 103.817 & -.222 & .271 & 1.432 & .535 \\
\hline Valid N (list wise) & 79 & - & - & - & - & - & - & - & - & - \\
\hline
\end{tabular}

Table 1: Descriptive statistics on SPSS. 


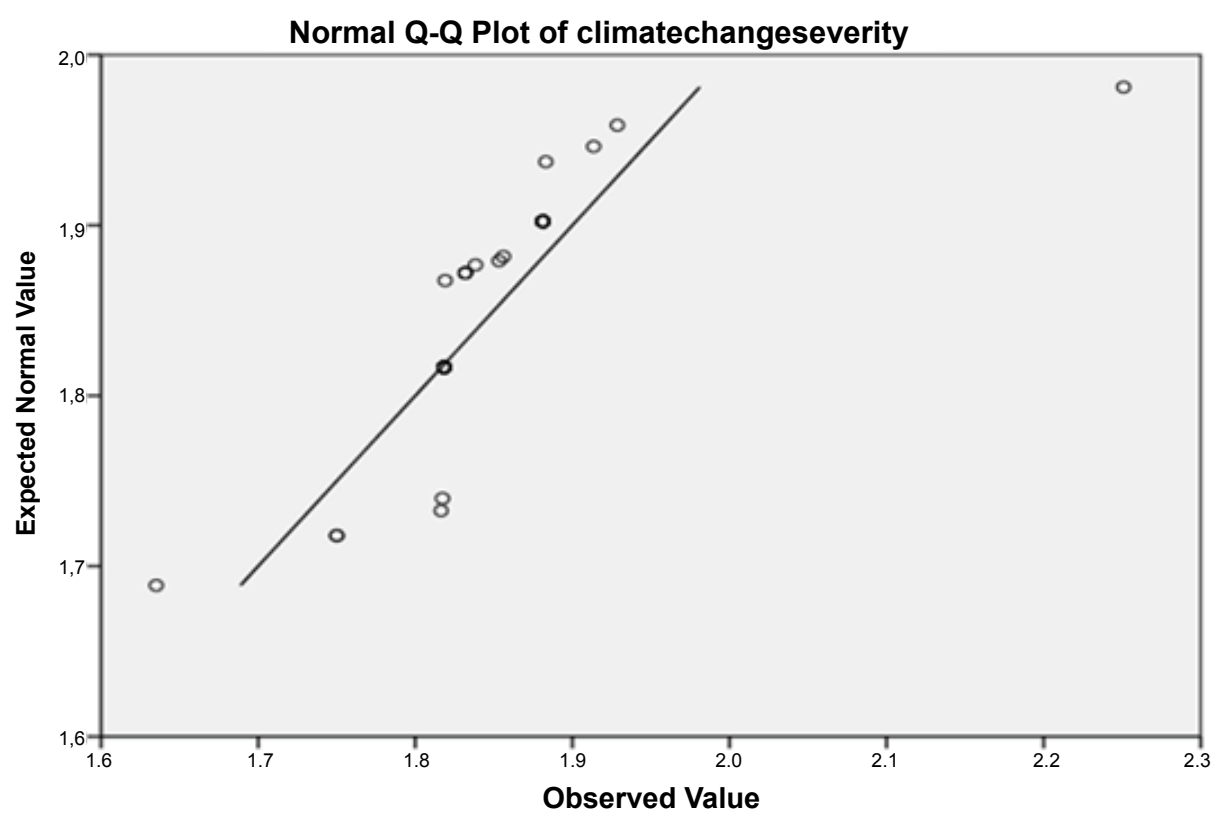

Figure 1: Q-Q plot of climate change severity.

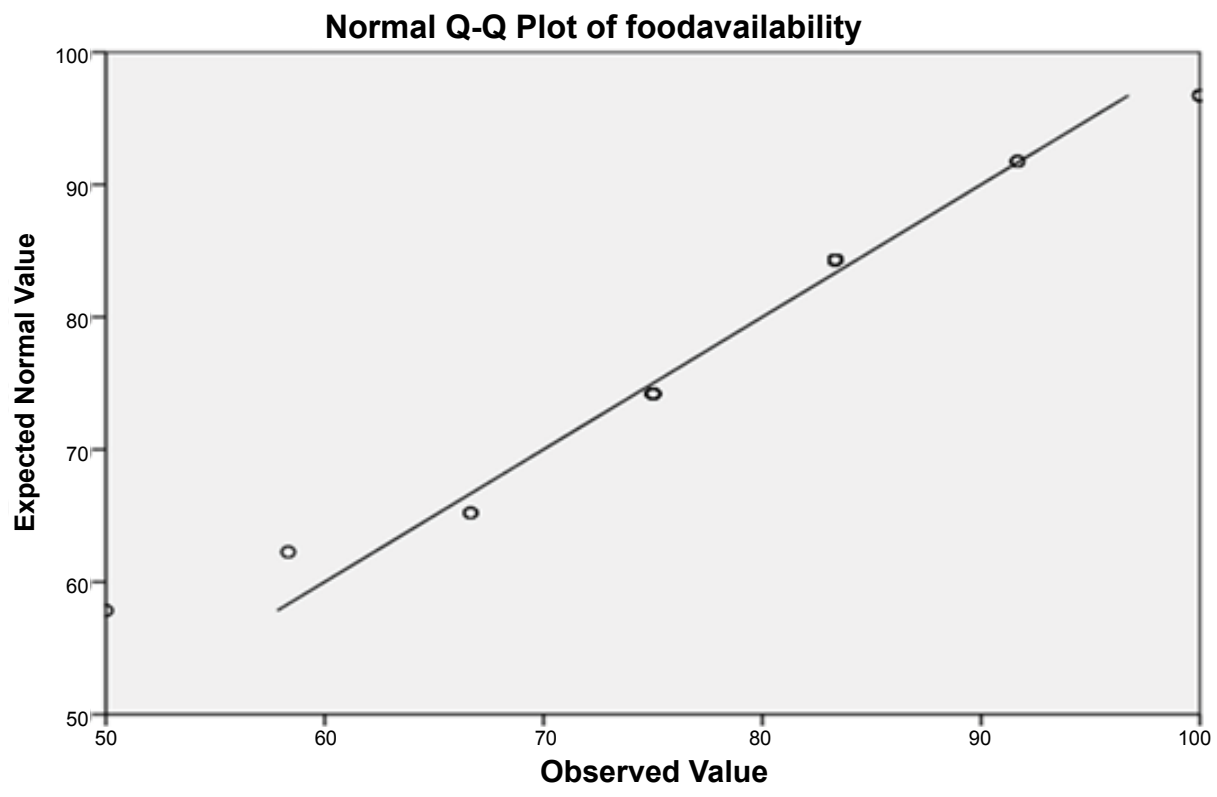

Figure 2: Q-Q plot on SPSS.

change and other risks. It is one part of the changes in household's decision making on production structure. However, the farmer's experiences on the way to adapt with climate variability are influenced by other factors.

The local people's responses and adaptation to climate changes in production structure cannot be understood in isolated from other factors as their decision making process is complex. Adaptation ways to climate change are related to many factors such as government policy, natural conditions, and climate condition, market price of agriculture products and household conditions, which were considered in the analysis of adaptation. Farmer's decision making process is complex in that they face many risks related to their production structure. Risks are related to climate variability, policy strategies, market price and agriculture production.

Basing on findings from field survey, there are many factors affecting farmer's decisions in term of adaptation of the activities that those farmers do in order to reduce risk and take advantage of opportunities. My study also shows that the factors on the decision making on production structure of farmers that are most important include flood water, salinity intrusion, drought, cyclone, market price and food security. Different adaptation ways led to different strategies on livelihood of farmers. My fieldwork results reinforce this concern 
Citation: Kabir MH, Ahmed Z, Khan R (2016) Impact of Climate Change on Food Security in Bangladesh. J Pet Environ Biotechnol 7: 306 . doi: 10.4172/2157-7463.1000306

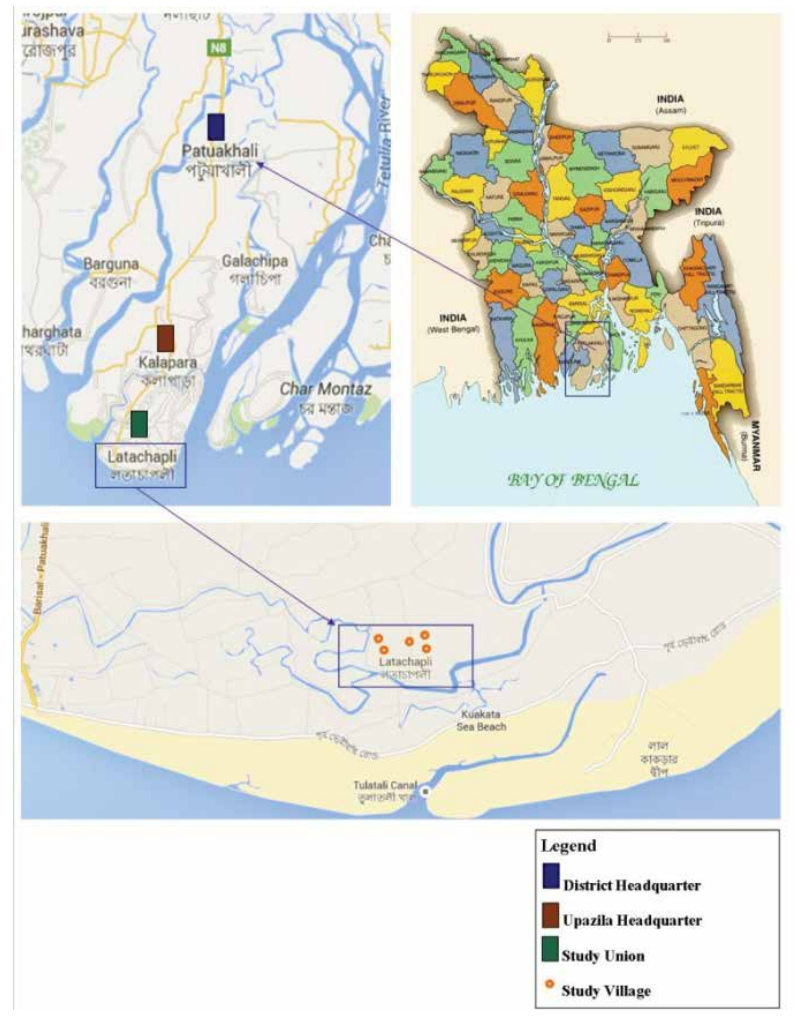

Figure 3: Study area.

as findings show how farmers' struggle with the new risk of increased insect attacks, irregular rain and drought periods.

We conclude that the climate change does not have significance effect on the food availability, food security and the adoption of an adaptation strategy, which may suggest a good adaptation strategy adopted by the farmers, testing the effect of the adoption of adaptation strategies on the climate change severity weakens this theory and suggest that these adaptation strategies does not affect the climate change, these results are counter intuitive and does not fit the literature review, which lets us with one possibility which is survey questioner that does not fit the research questions, the climate change survey was about climate change events that happened during the last 30 years which may have no effect on the current food security situation, but the lack of relation between the adoption of adaptation strategies and the food security level may suggest that the farmers are indifferent and immune to these variations maybe due to the different strategies adopted to counter those disasters. Farmers are currently using their traditional knowledge to cope with changes in climatic patterns. In order to achieve more efficient results regarding adaptation and benefit sharing, these local measures should be combined with advanced, scientifically-tested techniques. The Government has set up effective and extensive institutional mechanisms and established dedicated funds from its own sources to take measures to adapt and mitigate climate change events.

Also we found that the basic education level is increasing in between the farmers if we check generation wise education level but the still the wife's and girls are work as housewife. Though they have completed their basic education but no one is considering as an earning member of the family. We think if they can involve in some kind of small business which can be done from home then the economic condition of the family can increase little bit.

\section{References}

1. Walsh BM (2014) Simultaneous ground- and space-based observations of the plasmaspheric plume and reconnection. Science 343: 1122-1125.

2. David (2007) Climate change 2007: Mitigation. Contribution of working group III to the Fourth Assessment Report of the Intergovernmental Panel on Climate Change (IPCC).

3. Ayers $J(2010)$ Understanding the adaptation paradox: Can global climate change adaptation policy be locally inclusive. The London School of Economics and Political Science.

4. Schneider SH (1989) The greenhouse effect: Science and policy. Science 243 771-781.

5. Hoegh-Guldberg BJF (2010) The impact of climate change on the world's marine ecosystems. Science 328: 1523-1528.

6. Mirza MMQ (2011) Climate change, Flooding in South Asia and implications Regional Environmental Change 11: 95-107.

7. http://www.ft.com/cms/s/0/584ed992-4216-11e3-9d3c-00144feabdc0 html\#axzz3tMhfXymc

8. FAO (1996) Policy Brief.

9. Capone DN (2014) Food system sustainability and food security: Connecting the dots. Journal of Food Security 2: 13-22.

10. Sikder XJ (2014) Climate change impact and agriculture of Bangladesh Journal of Environment and Earth Science 4: 35-40.

11. Mainuddin K, Quasem S (2011) Planning and costing agriculture's adaptation to climate change in the salinity-prone cropping system of Bangladesh.

12. Streatfield KZA (2008) Population challenges for Bangladesh in the coming decades. J Health Popul Nutr 26: 261-272.

13. Subbarao k, Ninno C (2005) Food aid and food security in the short- and long run: Country Experience from Asia and sub-Saharan Africa.

14. BARC (2003) DAE SIDATAC Project.

15. Lagos JE (2015) Bangladesh grain and feed annual. GAIN Report Number: BG5003.

16. Disaster Dictionary (2009) Dhaka.

17. FAO (2007) Conference proceeding.

18. Wassmann DL (2009) Climate change affecting rice production: The physiological and agronomic basis for possible adaptation strategies. Advances in Agronomy 101: 59-122.

19. Hossain A, Silva T (2013) Wheat and rice, the epicenter of food security in Bangladesh. Songklanakarin J. Sci. Technol. 35: 261-274.

20. Karim QA, Abdool Karim SS, Frohlich JA, Mlisana KP, Mlotshwa M, et al (2010) Effectiveness and safety of tenofvir gel, an antiretroviral microbicide, for the prevention of HIV infection in women. Science 329: 1168-1174.

21. Miyan MA (2015) Droughts in Asian least developed countries: Vulnerability and sustainability. Weather and climate extremes.

22. Mahmood SAI (2012) Impact of climate change in Bangladesh: The role of public administration and government's integrity. Journal of Ecology and the Natural Environment 4: 223-240.

23. Phiri IP (2010) Modelling farmers' choice of adaptation strategies towards climatic and weather variability.

24. IPCC (2012) Special report

25. Swift J (1993) Understanding and preventing famine and famine mortality. The political analysis of markets $4: 1-28$

26. SPORE (2008) Climate change. Spore Special Issue.

27. DeWalt BR (1994) Using indigenous knowledge to improve agriculture and natural resource management. Human organization 53: 123-131.

28. Maddison D (2007) The perception of and adaptation to climate change in Africa. Washington, DC. 
Citation: Kabir MH, Ahmed Z, Khan R (2016) Impact of Climate Change on Food Security in Bangladesh. J Pet Environ Biotechnol 7: 306 . doi: 10.4172/2157-7463.1000306

Page 6 of 6

29. Hoddinott J, Kinsey B (2001) Child growth in the time of drought. Oxford Bull Econ Stat 63: 409-438.

30. Pittock AB (2011) Climate change: The science, impacts and solutions. 2nd ed Collingwood: CSIRO Publishing.

31. Ecker O, Breisinger C (2012) The food security system. International Food Policy Research Institute.

32. Philip AL, Gerlach SC (2009) Food, culture, and human health in Alaska: An integrative health approach to food security. Environmental Science and Policy 12: $466-478$.

33. Luther T (1999) The economics of global food security. Review of Agricultura Economics 21: 473-488.

34. Iqbal MJ, Alam KG (2010) Monitoring the spatio temporal variations in aerosols and aerosol-cloud Interaction over Pakistan using MODIS data. Adv. Space Res 46: 1162-1176.

35. Hossain KM, Nasren P (2008) Climate change and livelihood in Bangladesh: Experiences of people living in coastal regions.

36. Selvaraju R (2006) Livelihood adaptation to climate variability and change in drought prone areas of Bangladesh. ADPC.

37. Amir J, Mobarak AM, Guiteras RP (2015) Satellites, self -reports, and submersion: Exposure to floods in Bangladesh.

38. Lazar MAZM (2015) Agricultural livelihoods in coastal Bangladesh under climate and environmental change - A model framework. Journal of Environmental Monitoring 17: 1018-1031.

39. Toufique IA (2014) Assessing risks from climate variability and change fo disaster-prone zones in Bangladesh. International Journal of Disaster Risk Reduction 10: 236-249.

40. Rosenzweig PML (1993) University of Oxford, Environmental Change Unit.

41. Yokozawa M, Sakamoto YM (2009) Agro-ecological interpretation of rice cropping systems in flood-prone areas using modis imagery. Photogrammetric Engineering and Remote Sensing 75: 413-424.

42. Rahman F, Chowdhury S, Rahman M, Ahmed D, Hossain A (2009) Antimicrobia resistance pattern of gram-negative bacteria causing urinary tract infection. Stamford Journal of Pharmaceutical Sciences 2: 44-50.

43. Hugh B, Turral FJ (2011)Climate change water and food security.

44. Vermeulen SJ, Campbell BM (2012) Climate change and food systems. Annual Review of Environment and Resources 37: 195-222.

45. Rosegrant CSA (2003) Global food security: Challenges and policies. Science 302: 1917-1918.

46. Adams RM, McCarl BA, Dudek DJ (1998) The implications of global change for western Agriculture. West J Agric Econ 13: 348-356

47. Milliman JD, Broadus JM (1989) Environmental; and economic implications of rising sea level and subsiding deltas: The Nile and Bengal examples. Ambio 18: $340-345$

48. MLCTR, Parry KNT (2013) The impact of climatic variations on agriculture. Climatic Change 1: 95-110.

49. http://sciencewebpublishing.net/jacr/archive/2014/August/pdf/Tanko\%20 and $\% 20$ Muh

50. Devereaux S (2004) Transformative social protection. IDS Working Paper 232.

51. Titi SN (1994) Adaptive strategies of the poor in arid and semi-arid lands in search of sustainable livelihoods. Working Paper.

52. Rosenzweig S, Binswanger M, Dercon R (2013) World Institute for Development Economics.

53. Washington R (2006) Cooper PJM, 2008.

54. Washington R (2010) Cooper PJM, 2011.
55. Ahmed (2010) Sustaining livelihoods opportunities for the coastal poor under climate change: A case study from Bangladesh, Brisbane.

56. Gregory PJ (2005) Climate change and food security. Philosophica Transactions of the Royal Society B: Biological Sciences 360: 2139-2148.

57. IPCC (2014) Cambridge University Press, Cambridge.

58. World Bank (2013) Annual Report.

59. Rennie (1996) Participatory research for sustainable livelihoods. International Institute for Sustainable Development.

60. Frankenberger GD (1990) Food security, coping strategies and environmental degradation. Arid Lands Newsletter 30: 21-27.

61. Burke M, Lobell D (2010) Chapter 8: Food security and adaptation to climate change: What do we know. Climate Change and Food Security 37: 133-153.

62. FAO (2008) The state of food and agriculture 2008.

63. IRDB (2015) State of the Bangladesh economy in fiscal year 2015. Centre for Policy Dialogue.

64. Marketing (2012) Fortnightly food grain outlook. Department of Agricultural Marketing.

65. Ecker BC (2012) The Food Security System

66. Amir KI (2013) Climate change and its impact on food security in Bangladesh A case study on Kalapara, Patuakhali, Bangladesh. J Earth Sci Clim Change 4: 155 .

67. Bhargave V (2002) Global issues for global citizens.

68. CARE (2011) International Annual Report.

69. BRAC (2003) Impacts of climate change on cropping pattern in coastal region of Bangladesh.

70. FAO (2007.) Special Report.

71. MoEF (2009a) Special Report.

72. ICRIER (2012) Impact of climate change on agriculture and food security.

73. Miah MU (2010) Assessing long-term impacts of vulnerabilities of crop production due to climate change in coastal areas of Bangladesh. National Food Policy Capacity Strengthening Programme.

74. CDMP (1999) Livelihood Adaptation to Climate Change Project.

75. Hardy B, Pandey S (2007) Economic costs of drought and rice farmers' coping mechanisms: a cross country comparative analysis. International Rice Research Institute.

76. T. N. A. Press (2010) America's Climate Choice.

77. http://data.worldbank.org/country/bangladesh

78. B. B.O Statistics (2008) National Survey.

79. FAO (1997) Special report.

80. Philip SG, Loring A (2009) Food, culture, and human health in Alaska: an integrative health approach to food security. Environmental Science \& Policy 12: $466-478$. 